Professor Liliana IONESCU-FELEAGĂ, PhD (Corresponding author)

E-mail: liliana.feleaga@cig.ase.ro

Department of Accounting and Audit

The Bucharest University of Economic Studies

Professor Bogdan-Ștefan IONESCU, PhD

E-mail: bogdan.ionescu@ cig.ase.ro

Department of Management Information Systems

The Bucharest University of Economic Studies

Lecturer Mariana BUNEA, PhD

E-mail: mariana.bunea@cig.ase.ro

Department of Accounting and Audit

The Bucharest University of Economic Studies

\title{
EXPLORING THE ROMANIAN STUDENTS' INTENTION TO USE THE INTERNET OF THINGS FOR SUSTAINABLE EDUCATION
}

\begin{abstract}
The Internet of Things (IoT) represents an emerging technology that integrates various physical and virtual objects into a global network in order to allow the interaction and communication between them. The IoT strength is represented by the high impact on many everyday life aspects, and on the quality of life of potential users. In the same time, the IoT brings enormous challenges and opportunities to the higher education, as these technologies are useful not only in improving the core values of teaching and research or in measuring and analyzing various parameters of the educational environment, but also they create a new interaction between people and the educational environment within an organization. The objective of this research is to explore Romanian students intention to use the Internet of Things for educational purposes. The research method is represented by a survey, and the data collection tool is an online questionnaire. The results show that while learning effectiveness, ease of use, facilitating conditions and training have a significant influence on the intention to use IoT technologies, gender is an irrelevant variable.

Keywords: Internet of things (IOT); Education; Intention to use; Ease of use; Sustainability.
\end{abstract}

JEL Classification: I23, I21, L86, M20

\section{Introduction}

The sustainability of production and consumption from an economic, social and environmental point of view is the main challenge to which society as a

DOI: 10.24818/18423264/55.2.21.07 
whole must react today. The consumption and production patterns used in the last century have been unsustainable and have contributed massively to air, water and soil pollution, increasing waste, depletion of resources and global warming, all of these effects becoming real threats to life on earth. But many of the modern aspects of our society are based on the global success of the IT industry, which means that information and communication technology (ICT) also contributes to environmental issues, especially high energy consumption and greenhouse gas emissions. Thus, data centers consume approximately $3 \%$ of the global electricity supply, with an estimated annual increase of $20 \%$ in total consumption (Wang et al., 2017), given that these centers supply music streaming and video, social networking, entertainment and cloud computing. Moreover, the servers generate heat and, in order to keep them cold, huge amounts of energy are consumed. Data centers are responsible for about $2 \%$ of total greenhouse gas emissions, with the same carbon footprint as the airline industry. It is estimated that by 2040, carbon emissions from the production and use of electronic devices, including devices such as PCs, laptops, monitors, smartphones and tablets, will reach up to $14 \%$ of total emissions, which is half of current emissions of the global transport sector (World Economic Forum, 2019). To the two major problems is added the fact that IT operations generate electronic waste (e-waste). This waste accounts for approximately $70 \%$ of toxic waste, respectively $2 \%$ of solid waste, thus, experts estimate that global e-waste production is about to reach 120 million tones per year by 2050, representing one of the components that records the fastest growth rate (World Economic Forum, 2019). This waste is formally recycled in a small proportion, most of it being recycled informally or in landfills, which has an impact on health, pollution and reserves of rare and valuable raw materials.

Although digital transformation has many adverse effects, the IoT promises to provide solutions for a more intelligent, efficient and conscious management of natural resources (Maksimovic, 2017). This promise is in line with the sustainability principle that assumes current needs are met without compromising the ability of future generations satisfying their own. IoT is a network of intelligent objects and devices, connected and equipped with unique identifiers, to communicate and transfer data without human or computer interaction. IoT technologies are used in various fields (healthcare, smart homes, telecommunications, transportation etc.), but education represents one of the sectors which gets instant benefits from this technology development (Agrawal and Mittal, 2019). IoT implementation has a huge impact on the lives and behavior of potential users, contributing to the increase of the quality and satisfaction of life, safety and security, and improving innovation in society and sustainability. Thus, it is important how new technologies are perceived by users. When they perceive them to be useful and easy to use, they are more likely to accept them (Davidoff et al., 2006).

Our study investigates the intention to use IoT technologies by Romanian students, at a time when the popularity of the technology significantly changes the skills required by the labor market, the expectations on the quality of life and the

DOI: $10.24818 / 18423264 / 55.2 .21 .07$ 
Exploring the Romanian Students' Intention to Use the Internet of Things for Sustainable Education

education for sustainable development which helps students understand their professional responsibilities, abilities and personal motivations. The results highlight that while learning effectiveness, ease of use, facilitating conditions and training have a significant influence on the intention to use IoT technologies, the gender diversity is an irrelevant variable.

The content of this research is structured as follows: section 2 which is intended to review the relevant literature related to the association between IoT, sustainability and the impact on the education system. Section 3 contains the research methodology, followed by the results and discussions included in section 4, while the last section comprises the conclusions, implications and future directions of this research.

\section{Literature review}

IoT is a technology that provides the ability to link objects and transfer data to each other, through information detection devices, according to specific protocols. In other words, through IoT, various physical and virtual objects are integrated into a global network that allows communication or interaction with the internal and external environment (Atzori et al., 2010). In this way, everyday physical objects are converted into intelligent objects, which may be perfectly integrated into the global cyber infrastructure. Moreover, new connection alternatives are emerging, with connectivity being possible for any object and person within the network, at any time and in any place, in order to achieve the goal of intelligent identification, monitoring and management of things. These connection alternatives are able to extend the communication between "human to human", "human to things" and "things to things", and to transform both the society and economy as much as the internet did it in the past (Chen et al., 2014).

IoT is growing rapidly and has a significant impact on the internet, as this technology involves billions of physical devices around the world that have digital sensors and are interconnected through the use of various networks. Thus, if at the end of 2018, there were approximately 22 billion IoT connected devices, forecasts show that by 2030, their number will increase to 50 billion (www.statista.com). These forecasts are based on the fact that as the hardware and software sophistication of the consumer electronics industry increases, the number of produced electronic devices with internet connectivity will also continue to increase. This will create a massive network of interconnected devices that will cover everything, starting with smartphones, continuing to household appliances. The ability to interact in everyday life with a lot of objects connected to the internet allows individuals to access unlimited information, anytime and from anywhere, which creates premises for new ideas and developments.

To companies, the economic growth of IoT-based services is significant. From this perspective, the most obvious consequences are visible in areas such as automation and industrial manufacturing, logistics, business and process management, and intelligent transport of persons and goods. In addition, there are

DOI: 10.24818/18423264/55.2.21.07 
added projects such as Smart Home, which can support personalized user-centered healthcare and help increase people's quality of life at home (Chen et al., 2009), or Healthcare and related IoT-based services such as m-Health and telecare, which enable the efficient provision of medical health services, prevention, diagnosis, treatment and monitoring through electronic means (Al-Fuqaha et al., 2015). Also of great interest are the development of IoT applications for monitoring children, telemonitoring and care for elders, education transformation, monitoring of environment and increase of sustainability etc., these technologies provide a great market opportunity not only for equipment manufacturers and internet service providers, but also for application developers. In fact, it is estimated that the IoT will reach a total economic impact of over 11 trillion dollars per year by 2025 .

As IoT becomes a ubiquitous technology, it is essential to consider its effects on ecological, economic and societal development, because the term „quality of life" is synonymous with sustainability and sustainable development. In other words, the concept of sustainable development is based on the idea of ensuring a better quality of life for everyone, now and for future generations. Many factors contribute to improving or worsening the quality of life in terms of sustainability and it is clear that if we do not all adopt more sustainable lifestyles, the quality of life for the population will deteriorate. For this reason, we must recognize that the development of IoT has been rapid and varied, and insufficient attention has always been paid to the proper use of technology for an intelligent life as a whole. In other words, the long-term impact on sustainable development is still unclear, researchers often claiming that the advanced application of IoT technology has a number of risks, in particular related to the consumption of raw materials and energy, waste management and air pollution. Thus, the production and maintenance of the necessary IoT hardware components involve a high consumption of raw materials, the extraction of which directly consumes the earth's mass and sometimes pollutes areas that can no longer be exploited to full capacity and in the desired manner. In addition, some of the raw materials included in the production process are not completely consumed and are often polluted or mixed with other chemicals, requiring a complex recycling process or special measures in order to dispose them in a safe manner (Pramanik et al., 2019). Another threat to sustainability is represented by a high energy consumption of IoT systems, especially if fossil resources are used to produce the necessary energy. Data centers, which process large amounts of data, are primarily responsible for this consumption. To these are added the multitude of smart devices that are part of IoT networks, but also sensors and devices powered remotely by batteries (Maksimovic, 2017). Another threat to human health and the environment is the implementation of IoT systems requiring the replacement of existing systems and technologies with a large number of electronic devices, which by their nature have short lifetimes, resulting in a large amount of electronic waste, difficult to recycle, due to the high content of non-degradable material (Maksimovic, 2017). It is known that e-waste represents a significant part of hazardous waste from landfills, which release significant amounts of heavy metals, toxic substances and volatile chemicals (Pramanik et al., 2019). The situation becomes even more critical given 
Exploring the Romanian Students' Intention to Use the Internet of Things for Sustainable Education

that the IT sector is one of the biggest polluters and the manufacture of billions of IoT devices, their delivery, operation and excessive use of radio access networks will continue to increase greenhouse gas emissions (Popli et al., 2019), contributing to the destruction of the ozone layer, higher disease rates and global warming.

However, the use of IoT is linked to opportunities to improve various aspects of sustainability, especially in the area of smarter, more efficient and conscious management of natural resources. Besides the fact that IoT is an instrument of economic growth, it is also a facilitator of sustainability and climate change projects, trying to contribute to "a smarter, greener, fairer and more efficient world" (Maksimovic, 2017). Nowadays, there are already many solutions in place that combine IoT and sustainability, while their creators take an active role, both in aligning IoT devices with international climate protection standards and in putting IoT into operation, in favor of the environment. For example, IoT provides the functionality that is needed to achieve the Circular Economy vision. This is an industrial system in which resources are used in a closed cycle, meaning that their components will be fully recovered, recycled and reused after utilization (Murray et al., 2017). Also, smart buildings and IoT-connected infrastructure, as well as intelligent transportation could reduce energy consumption. According to the World Economic Forum (2019), so-called smart energy or energy used in IoT networks and sensors for storing and distributing information would allow greater efficiency, while reducing the price of $\mathrm{kW}$ and increasing the use of renewable energy compared to other energy sources. This could lead to energy savings of over 1.3 trillion MWh from now until 2030. Moreover, IoT can also have a positive influence on waste generation, acting on the useful life of hardware components. This can be done by remotely monitoring and updating the product firmware or digital components, or by using specific design principles, such as Open-Source, which allow users to repair, upgrade, or customize their own IoT systems (Sas and Neustaedter, 2017). Consequently, by monitoring obsolescence, the damage to certain components can be identified and repaired before it affects the other components of the product (Li et al., 2017). However, reducing greenhouse gas emissions remains one of the key objectives in order to mitigate the consequences of climate change. IoT can significantly contribute to this goal through the Smart Traffic project. Travel patterns are analyzed and used in order to optimize the early preparation of public transport vehicles, to increase occupancy and reduce the number of vehicles engaged in traffic, which means less GHG emissions (Davidsson et al., 2016). A decrease in emissions in this area is also achieved by optimizing traffic routes according to the occupancy rate, the number and period of traffic jams.

However, human behavior plays the most important role in shaping the path to sustainability. IoT technology has a high potential to help improve human behavior in terms of sustainability, because it allows high-quality analysis and recommendations in relation to individual patterns of behavior. Based on these, the improved human behavior contributes to an increase in sustainability by raising the level of awareness. For example, by implementing smart meters, which are smart grids components (Smart Grid), users receive real-time feedback on the level of

DOI: 10.24818/18423264/55.2.21.07 
energy consumed by their houses, learn about the causes, and tend to improve their sustainable behavior. A key issue in this context is how individuals perceive these new IoT technologies. Studies show that when these technologies are perceived to be useful and easy to use, individuals are more likely to accept them (Davidoff et al., 2006). Moreover, the acceptance of new technologies and their sustainable use are closely linked to education, and universities are considered agents of change in respect to many issues, including sustainability awareness, in the context of the economy's digital transformation (Mochizuki and Fadeeva, 2010).

Education is one of the major elements of sustainability and the IoT has an extraordinary potential to reform the education, by hiring and motivating teachers, students, administrative staff, and by increasing the learning curve. Thus, new technologies help teachers to manage the necessary equipment for teaching activities, to initiate and manage class sessions with voice / facial / gestural commands, to communicate with students from the distance, in different locations, to confirm the identity of students and to identify their special needs, to keep on collecting feedback from students and to evaluate their behavior, performance, interest and participation in the activities carried out (Jiang, 2016). In turn, students use IoT primarily for communicating with colleagues, exchanging data for projects, discussing and annotating real-time learning materials, and accessing learning resources from the distance, including tailored resources based on location, time, date, interactions between students, level of knowledge etc. The administrative staff of a university needs IoT to manage and supervise academic resources. Data collected from the process of monitoring the portable equipment (various portable projectors, laboratory equipment, sports equipment etc.) can be used to automatically generate patterns and trends and, to find potential inefficiencies and establish the necessary measures to remedy them. Staff can also use IoT technologies in order to be able to manage events, respectively to monitor and maintain the psychological health of students and teachers, or to increase overall safety and security (Elyamany and AlKhairi, 2015).

For education, IoT does not represent just an instrument or delivery system, but it has to be perceived as a set of resources and permissions that provide an opportunity to rethink educational goals and methods within the institutions. There is a need for a deeper understanding of technology, algorithms and hypotheses integrated into smart systems, but, in addition to this imperative digital literacy, it is essential that students are able to assess the sources and credibility of the information they receive and understand what are the psychological, social, economic and environmental effects of technology. In other words, the truly transformative potential of IoT technologies can only be exploited in the context of a converted educational system which is focused on transversal skills, which will guide students towards a prosperous and sustainable future. Given that the digital transformation of both the economy and society makes the modern world more complex and dynamic, it is imperative that education remains connected to the trends that shape the world in which we live. Consequently, students have no choice but to accept technology that, in the context of sustainable education, will develop their creative, strategic and analytical thinking in order to help them 
Exploring the Romanian Students' Intention to Use the Internet of Things for Sustainable Education

successfully meet the new challenges of the labor market, increasing their quality of life.

\section{Materials and Methods}

In this study, the research methodology used is predominantly quantitative, based on a deductive statistical analysis, which allowed testing and identifying the cause-effect connections and assessing their significance through SPSS software version 20.0. The objective is to investigate the intention to use IoT technologies by the Romanian students, given the emergence of new expectations on the labor market. In order to achieve this objective, the authors prepared and transmitted during October-November 2020, an online questionnaire among the students that are enrolled at different universities from Romania. Following the submission of the questionnaire, we received 1,179 valid answers. Given that the total number of students enrolled in bachelor's, master's and doctoral programs in Romania, in the academic year 2019-2020, was 407,373 (ANS, 2020), the sample of 1,179 is considered representative, because after reaching a volume of 700-800 respondents, the representativeness of the sample no longer increases significantly, regardless of the volume of population from which it is extracted (Rotariu, 1999).

The applied questionnaire was structured in two parts. The first part contains profile questions describing the analyzed sample. Table 1 shows the demographic composition of the respondents.

Table 1. Demographic and profile data of the respondents

\begin{tabular}{|c|c|c|c|}
\hline Variable & Alternative & $\begin{array}{l}\text { Number of } \\
\text { respondents }\end{array}$ & Structure \% \\
\hline \multirow[t]{2}{*}{ Gender } & Woman & 902 & 76.51 \\
\hline & Man & 277 & 23.49 \\
\hline \multirow[t]{4}{*}{ Age } & 18 - 20 years, & 660 & 55.98 \\
\hline & 21- 25 years, & 460 & 39.02 \\
\hline & $26-35$ years & 35 & 2.97 \\
\hline & $>35$ years & 24 & 2.04 \\
\hline \multirow{3}{*}{$\begin{array}{l}\text { Education } \\
\text { level }\end{array}$} & Bachelor & 931 & 78.97 \\
\hline & Master & 224 & 19.00 \\
\hline & $\begin{array}{l}\text { Doctoral studies } \\
(\mathrm{PhD})\end{array}$ & 24 & 2.04 \\
\hline Total & & 1179 & 100.00 \\
\hline
\end{tabular}

The demographic results indicate that more than half of the respondents are women, which is consistent with their high share among students enrolled in Romania (ANS, 2020). The age of most respondents is up to 26 years and are mainly enrolled in undergraduate programs $(78.97 \%)$.

DOI: 10.24818/18423264/55.2.21.07 
The second part of the questionnaire contains five sets of questions related to IoT technologies. In order to prepare the content questions, the Likert scale was used, containing five values and a set of sentences (questions), which represent favorable statements in which the subjects must specify the level of agreement, respectively disagreement in respect to the statements in the questionnaire. Using this scale allows the calculation of means and standard deviations to be able to make comparisons between groups of subjects. The response options included in the Likert Scale range from (1), representing a "strong disagreement" to (5) "strong agreement". The content questions addressed different factors that were identified in the literature as being most related to the acceptance and use of IoT technologies, including the intention for these IoT to be used. This intention represents an individual perception which leads to a specified behavior in the future (Fishbein and Ajzen, 1975). The identified factors are described in Table no. 2.

Table 2. Susceptible factors that might influence the intention to use IoT technologies

\begin{tabular}{ll}
\hline \multicolumn{1}{c}{ Factors } & \multicolumn{1}{c}{ Description factors } \\
\hline $\begin{array}{l}\text { Learning } \\
\text { effectiveness }\end{array}$ & $\begin{array}{l}\text { "The degree to which a person believes that the use of a } \\
\text { particular system leads to an increase in the performance } \\
\text { of his activities in an organizational context" (Davis, } \\
\text { 1989). }\end{array}$ \\
\hline Ease to use & $\begin{array}{l}\text { "The degree to which a person expects the use of a } \\
\text { particular system to be effortless" (Davis, 1989). }\end{array}$ \\
\hline Facilitating & $\begin{array}{l}\text { "The degree to which an individual believes that there is } \\
\text { an organizational and technical infrastructure that supports } \\
\text { the use of the system" (Venkatesh et al., 2003). }\end{array}$ \\
\hline Training & $\begin{array}{l}\text { Training on the use of IoT technology, related information } \\
\text { and related communications, supports users in } \\
\text { understanding, assessing and minimizing difficulties } \\
\text { arising from technological complexity (Mudaly et al., } \\
\text { 2013). }\end{array}$ \\
\hline \multicolumn{1}{c}{ Source: Own projection of the authors }
\end{tabular}

For data processing, correlation tests and regression analyzes were performed. Based on these, the following aspects were analyzed: (1) identifying the association through a logical analysis of the possibility of such a relationship between the variables that are considered; (2) determining the degree of link's intensity, using different parameters used in the correlation analysis; and (3) establishing the meaning and form of the association, by using specific methods which are characteristics of regression analysis. The correlation analysis represents a measure that is used to investigate the level of significance of the association between variables. It can be expressed by covariance, Pearson correlation coefficient, nonparametric correlation coefficients. At the same time, multiple regression analysis is used in the present research to evaluate the extent to which 
Exploring the Romanian Students' Intention to Use the Internet of Things for Sustainable Education

the dependent variable (Intention to use IoT - IU) can be influenced by means of independent variables (Learning effectiveness - TU, Ease to use - EOU, Facilitating Conditions - FC, Training - UT and Gender).

\section{Results and discussion}

This section describes the analysis of the relationship between the factors that may influence the intention to use IoT by the Romanian students. The significance of the relationship between the independent variables (as factors that facilitate or not the intention to use IoT) and the dependent variable (intention to use IoT) may have three levels, respectively low, high and moderate. In table no. 3 is presented the analysis of the relationship between predictors and dependent variables, respectively the partial correlation matrix, which comprises the Pearson correlation coefficients, the significance value (Sig.) for each correlation coefficient, and the number of cases considered in the study $(\mathrm{N})$.

Table 3. The partial correlation matrix (correlations)

\begin{tabular}{ccccccc}
\hline \multirow{4}{*}{ IU } & TU & EOU & FC & UT & Gender \\
\hline \multirow{7}{*}{$\begin{array}{c}\text { Pearson } \\
\text { Correlation }\end{array}$} & .729 & .484 & .612 & .497 & -.006 \\
\cline { 2 - 7 } & $\begin{array}{c}\text { Sig. (1- } \\
\text { tailed) }\end{array}$ & .000 & .000 & .000 & .000 & .418 \\
\cline { 2 - 7 } & $\mathrm{N}$ & 1179 & 1179 & 1179 & 1179 & 1179 \\
\hline \multicolumn{7}{c}{$* *$ Significant level $\mathrm{p}<0.01$} \\
\end{tabular}

Thus, according to the data presented in the table above, the results show that there is a significant positive relationship between the independent variables (learning effectiveness and ease to use) and the dependent variable - Intention to use IoT among students in Romania. The values of the Pearson coefficient for the two variables are 0.729 and, respectively 0.612 , which demonstrates that the predictors have a significant effect on the intention to use IoT by students in Romania. Regarding the independent variables EOU and UT, they have a moderate significance on the dependent variable, the Pearson coefficient registering values of 0.484 and, respectively 0.497 . According to the data in Table 4 , Gender variable is eliminated, because it has the weakest significance on the variable the intention to use IoT. SPSS first develops a model with all the independent variables, using the Enter method, then, in each step, creates a model, eliminating the variable that has the lowest contribution.

Table 4. Entered/Removed ${ }^{\text {a }}$ variables

\begin{tabular}{cccc}
\hline Model & $\begin{array}{c}\text { Entered } \\
\text { variables }\end{array}$ & $\begin{array}{c}\text { Removed } \\
\text { variables }\end{array}$ & Method \\
\hline 1 & Gender, & & Enter \\
\hline
\end{tabular}


Liliana Ionescu-Feleagă, Bogdan-Ștefan Ionescu, Mariana Bunea

\begin{tabular}{|c|c|c|}
\hline \multicolumn{3}{|c|}{$\mathrm{FC}, \mathrm{TU}^{\mathrm{b}}$} \\
\hline 2 & Gender & $\begin{array}{c}\text { Backward (criterion: } \\
\text { Probability of F-to-remove } \\
\qquad>=.100) .\end{array}$ \\
\hline
\end{tabular}

a. Dependent Variable: IU

b. All requested variables entered.

Table 5 shows for each regression model the value of the correlation coefficient $(\mathrm{R})$, the value of the coefficient of determination $\left(\mathrm{R}^{2}\right)$ and the standard error. The $\mathrm{R}^{2}$ value increases as more variables are entered into the model. The inclusion of irrelevant variables leads to an increase in the standard error.

Table 5. Multiple regression analysis - Model Summary ${ }^{\mathrm{c}}$

\begin{tabular}{|c|c|c|c|c|c|c|c|c|c|}
\hline \multirow[b]{2}{*}{ Model } & \multirow[b]{2}{*}{$\mathbf{R}$} & \multirow[b]{2}{*}{$\begin{array}{c}\mathbf{R} \\
\text { Square }\end{array}$} & \multirow[b]{2}{*}{$\begin{array}{l}\text { Adjuste } \\
\text { d R } \\
\text { Square }\end{array}$} & \multirow{2}{*}{$\begin{array}{c}\text { Std. } \\
\text { Error of } \\
\text { the } \\
\text { Estimate }\end{array}$} & \multicolumn{5}{|c|}{ Change Statistics } \\
\hline & & & & & $\begin{array}{c}\text { R } \\
\text { Square } \\
\text { Change }\end{array}$ & $\begin{array}{c}\text { F } \\
\text { Change }\end{array}$ & df1 & df2 & $\begin{array}{c}\text { Sig. F } \\
\text { Change }\end{array}$ \\
\hline 1 & $.778 \mathrm{a}$ & .606 & .604 & .58925 & .606 & 360.303 & 5 & 1173 & .000 \\
\hline 2 & $.778 \mathrm{~b}$ & .606 & .604 & .58902 & .000 & .072 & 1 & 1173 & .788 \\
\hline
\end{tabular}

a. Predictors: (Constant), Gender, EOU, UT, FC, TU

b. Predictors: (Constant), EOU, UT, FC, TU

c. Dependent Variable: IU

According to the data presented in Table 5, the values $\mathrm{R}$, adjusted $\mathrm{R}^{2}$ and the standard error show that the best predictors (independent variables that best estimate the dependent variable) are the variables TU, FC, followed by UT and EOU. The same conclusion is reached given the results presented in Table 6. If the significance of the F statistic is small (Sig is less than 0.05), then the independent variables explain the variation of the dependent variable.

Table 6. ANOVA ${ }^{\mathrm{a}}$

\begin{tabular}{llrrrrr}
\hline \multicolumn{1}{c}{ Model } & $\begin{array}{c}\text { Sum of } \\
\text { Squares }\end{array}$ & \multicolumn{1}{c}{ df } & $\begin{array}{c}\text { Mean } \\
\text { Square }\end{array}$ & \multicolumn{1}{c}{ F } & \multicolumn{1}{c}{ Sig. } \\
\hline 1 & Regression & 625.524 & 5 & 125.105 & 360.303 & $.000 \mathrm{~b}$ \\
\cline { 2 - 7 } & Residual & 407.290 & 1173 & .347 & & \\
\cline { 2 - 7 } & Total & 1032.814 & 1178 & & & \\
\hline 2 & Regression & 625.499 & 4 & 156.375 & 450.717 & $.000 \mathrm{c}$ \\
\cline { 2 - 7 } & Residual & 407.315 & 1174 & .347 & & \\
\cline { 2 - 7 } & Total & 1032.814 & 1178 & & & \\
\hline
\end{tabular}

b. Predictors: (Constant), Gender, EOU, UT, FC, TU

c. Predictors: (Constant), EOU, UT, FC, TU 
Exploring the Romanian Students' Intention to Use the Internet of Things for Sustainable Education

In Table 7 are presented the regression coefficients, and in the first part are shown the regression coefficients, the standard errors, the value of the test statistic $t$ for each coefficient, as well as the value of Sig. In the case of multiple regression, in addition to a simple correlation, the followings are presented: collinearity statistics, tolerance and variance inflation factor (VIF).

Table 7. Coefficients ${ }^{\mathrm{a}}$

\begin{tabular}{|c|c|c|c|c|c|c|c|c|c|c|}
\hline & & \multicolumn{2}{|c|}{$\begin{array}{l}\text { Unstandardized } \\
\text { Coefficients }\end{array}$} & \multirow{2}{*}{$\begin{array}{c}\text { Standardized } \\
\text { Coefficients } \\
\text { Beta }\end{array}$} & \multirow[b]{2}{*}{ t } & \multirow[b]{2}{*}{ Sig. } & \multicolumn{2}{|c|}{$\begin{array}{l}95.0 \% \text { Confidence } \\
\text { Interval for B }\end{array}$} & \multicolumn{2}{|c|}{ Collinearity Statistics } \\
\hline \multicolumn{2}{|c|}{ Model } & B & $\begin{array}{l}\text { Std. } \\
\text { Error }\end{array}$ & & & & $\begin{array}{l}\text { Lower } \\
\text { Bound }\end{array}$ & $\begin{array}{l}\text { Upper } \\
\text { Bound }\end{array}$ & Tolerance & VIF \\
\hline \multirow[t]{6}{*}{1} & (Constant) & .022 & .115 & & .193 & .847 & -.204 & .248 & & \\
\hline & TU & .528 & .023 & .529 & 23.005 & .000 & .483 & .574 & .635 & 1.574 \\
\hline & EOU & .165 & .029 & .125 & 5.649 & .000 & .108 & .223 & .684 & 1.463 \\
\hline & $\mathrm{FC}$ & .224 & .030 & .196 & 7.389 & .000 & .165 & .284 & .476 & 2.101 \\
\hline & UT & .079 & .024 & .078 & 3.249 & .001 & .031 & .127 & .578 & 1.731 \\
\hline & Gender & -.011 & .041 & -.005 & -.268 & .788 & -.091 & .069 & .982 & 1.018 \\
\hline \multirow[t]{5}{*}{2} & (Constant) & .018 & .114 & & .162 & .872 & -.206 & .242 & & \\
\hline & TU & .528 & .023 & .528 & 23.114 & .000 & .483 & .573 & .643 & 1.556 \\
\hline & EOU & .165 & .029 & .125 & 5.649 & .000 & .108 & .222 & .684 & 1.463 \\
\hline & $\mathrm{FC}$ & .225 & .030 & .197 & 7.448 & .000 & .166 & .284 & .480 & 2.083 \\
\hline & UT & .079 & .024 & .079 & 3.260 & .001 & .032 & .127 & .578 & 1.729 \\
\hline
\end{tabular}

a. Dependent Variable: Y

According to the data presented in Table 7, the regression equation is as follows: $\mathrm{Y}=0.18+.528 \mathrm{X}_{1}+.165 \mathrm{X}_{2}+.225 \mathrm{X}_{3}+.079 \mathrm{X}_{4}$, where: $\mathrm{Y}=$ Intention to Use IoT; $X_{1}=$ Learning effectiveness; $X_{2}=$ Ease to use; $X_{3}=$ Facilitating Conditions; $X_{4}=$ Training. Thus, the significant standardized coefficients for the four factors, respectively TU - Learning effectiveness $(\beta=.53, \mathrm{p}<.05)$, FC Facilitating Conditions $(\beta=.20, \mathrm{p}<.05)$, EOU - Ease to use $(\beta=.13, \mathrm{p}<.05)$ and UT - Training $(\beta=.08, \mathrm{p}<.05)$ show that the respective variables have a significant influence on the intention to use IoT among students in Romania. "gender".

Table 8 presents information related to the excluded independent variable -

Table 8. Excluded Variables

\begin{tabular}{|c|c|c|c|c|c|c|c|}
\hline \multirow[b]{2}{*}{ Model } & \multirow[b]{2}{*}{ Beta In } & \multirow[b]{2}{*}{$\mathbf{t}$} & \multirow[b]{2}{*}{ Sig. } & \multirow[b]{2}{*}{$\begin{array}{c}\text { Partial } \\
\text { Correlation }\end{array}$} & \multicolumn{3}{|c|}{ Collinearity Statistics } \\
\hline & & & & & Tolerance & VIF & $\begin{array}{l}\text { Minimum } \\
\text { Tolerance }\end{array}$ \\
\hline Gender & $-.005^{\mathrm{b}}$ & -.268 & .788 & -.008 & .982 & 1.018 & .476 \\
\hline
\end{tabular}

a. Dependent Variable: Y

b. Predictors in the Model: (Constant), EOU, UT, FC, TU

Beta in is the regression coefficient that would result if the removed variable would have been kept in the model for the following steps. The statistic

DOI: 10.24818/18423264/55.2.21.07 
test $\mathrm{t}$ and Sig. value are used in order to test the null hypothesis regarding the regression coefficients, i.e. the hypothesis that there is no significant relationship between the dependent variable and the predictors. In the present study, Sig values are found to be very large (compared to 0.05) which allows us to reject the null hypothesis in respect to no association between the dependent variable - Intention to Use and the dependent variable - Gender. There are also low values for tolerance and high values for VIF (mutual tolerance), which denotes the existence of multicollinearity, which leads to a large variance of the regression coefficient and, therefore, an instability of the estimate.

The confirmation of the hypotheses based on which the regression analysis was performed, is also graphically verified by using the P-P Plot and Scatterplot diagrams, according to figures 1,2 and 3.

Thus, based on the multiple regression analysis and the partial correlation matrix (Pearson correlation coefficient), we can conclude that the independent variables learning effectiveness, ease to use, facilitating conditions and training have a significant relationship with the dependent variable Intention to Use. Gender is the only excluded variable, in line with the research results, thus, it does not have a significant influence on the dependent variable - Intention to Use.

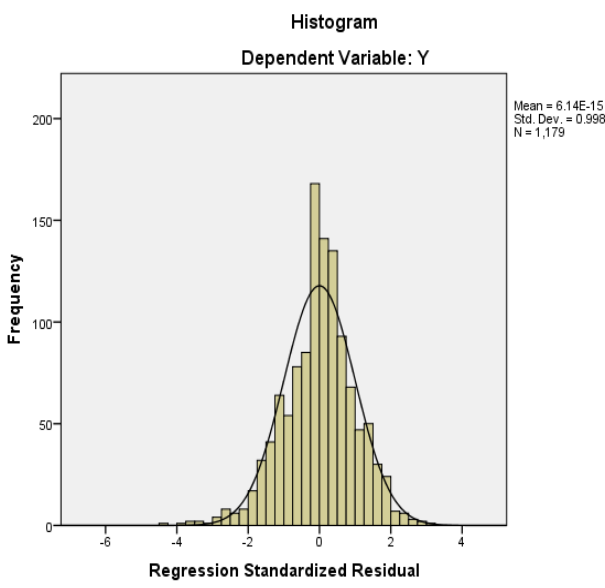

Figure 1

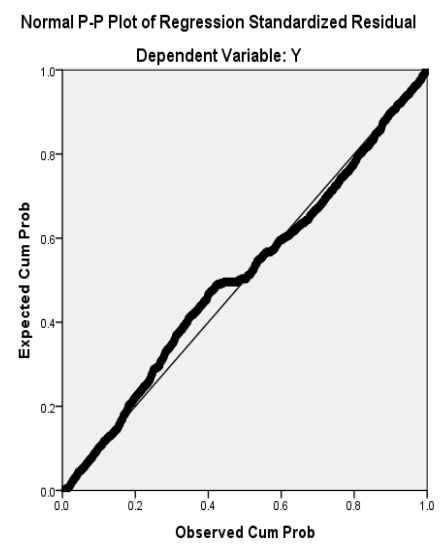

Figure 2 
Exploring the Romanian Students' Intention to Use the Internet of Things for Sustainable Education

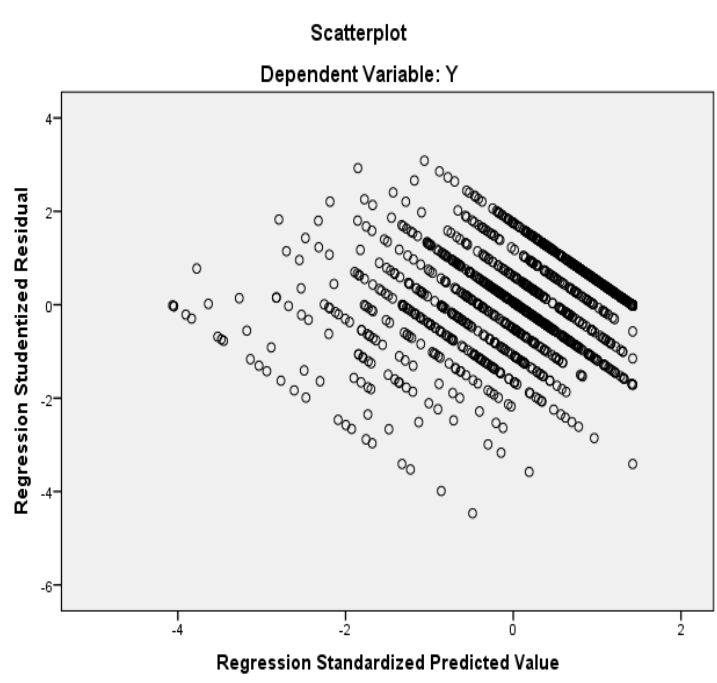

Figure 3

\section{Conclusions}

The objective of this research is to explore Romanian students' intention to use IoT for educational purposes and to analyze the predictors which are significantly associated, at a time when the popularity of technology significantly changes the expectations on the labor market, and the education for sustainable development helps the students to understand their professional responsibilities, abilities and personal motivations.

The results highlight that, while learning effectiveness, ease of use, facilitating conditions and training are significantly associated to the intention to use IoT technologies, gender diversity is not, being an insignificant variable. In the context in which human behavior plays the most important role in shaping the path to sustainability, IoT technology has a high potential to contribute to improving human behavior in terms of sustainability, as it is characterized by high quality analysis and recommendations in relation to individual patterns behavior. Consequently, the improved human behavior, which is based on these recommendations, contributes to the increase of sustainability by raising awareness. This is one of the reasons why we believe that the perception of students as future protagonists in the labor market and as users of the benefits and opportunities offered by IoT, is associated with the sustainable use of these technologies, thus contributing to increasing the quality of life in the context of respect for the environment, while realizing the importance of the proper use of technology for an intelligent life as a whole.

The main contribution of our research is that it provides important information about the impact of the motivational spectrum on the use of IoT solutions by students, as future protagonists in a labor market that requires

DOI: 10.24818/18423264/55.2.21.07 
increasingly different skills, compatible with respecting the sustainability of production and economic, social and environmental consumption.

The results of this study are based on a group of very young students (over 95\% aged between 18 and 25) from a small geographical area. There is much scope for further research in this area. The sample could be extended to include students from other geographical areas, to identify and analyze the differences in the perception and behavior from one country to another, depending on political, social, cultural, religious factors. Moreover, research can be extended to professionals in the sectors most affected by the development of IoT technologies.

\section{REFERENCES}

[1] Agrawal, S. R., Mittal, D. (2019), Constructive Usage of Whatsapp in Education Sector for Strengthening Relations. International Journal of Educational Management, 33(5): 954-964;

[2] Al-Fuqaha, A., Guizani, M., Mohammadi, M., Aledhari, M., Ayyash, M. (2015), Internet of Things: A Survey on Enabling Technologies, Protocols, and Applications. IEEE Commun. Surv. Tutor. 17(4), 2347-2376;

[3] ANS (2020), Platforma naţională de colectare a datelor statistice pentru învăţământul superior [online]. Available at: www. https://date.invatamantsuperior.ro/. Accessed 20 November 2020;

[4] Atzori, L., Iera, A. Morabito, G. (2010), The Internet of Things: A Survey. Computer Networks, 54(15): 2787-2805;

[5] Chen, L., Nugent, C., Mulvenna, M., Finlay, D., and Hong, X. (2009), Semantic Smart Homes: Towards Knowledge Rich Assisted Living

Environments. In Intelligent Patient Management Studies in Computational Intelligence (pp.279-296), volume 189; Berlin, Heidelberg: Springer;

[6] Chen, S., Xu H.; Liu D.; Hu B.; Wang H. (2014), A Vision of Iot: Applications, Challenges, and Opportunities with China Perspective. IEEE Internet of Things journal, 1(4): 349-359;

[7] Davidoff, S., Lee, M.K., Zimmerman, J., Dey, A.K. (2006), Socially-Aware Requirements for a Smart Home. In Proceedings of the International Symposium on Intelligent Environments: 41-44;

[8] Davidsson, P., Hajinasab, B., Holmgren, J., Jevinger, Å., Persson, J.A. (2016), The Fourth Wave of Digitalization and Public Transport: Opportunities and Challenges. Sustainability, 8(12): 1-16;

[9] Davis, F., (1989), Perceived Usefulness, Perceived Ease of Use and User Acceptance of Information Technology. MIS Quarterly, 13(3): 319-340; [10] Elyamany, H.F., AlKhairi, A.H. (2015), IoT-academia Architecture: A Profound Approach. IEEE/ACIS 16th International Conference on Software Engineering, Artificial Intelligence, Networking and Parallel/Distributed Computing (SNPD): 1-5; 
Exploring the Romanian Students' Intention to Use the Internet of Things for Sustainable Education

[11] Fishbein, M., Ajzen, I. (1975), Belief, Attitude, Intention and Behavior: An Introduction to Theory and Research.

https://people.umass.edu/aizen/f\&a1975.html. accessed 14 November 2020;

[12] Jiang, Z. (2016), Analysis of Student Activities Trajectory and Design of

Attendance Management Based on Internet of Things. International Conference on Audio, Language and Image Processing (ICALIP): 600-603;

[13] Li, C.S., Darema, F, Chang, V. (2017), Distributed Behavior Model

Orchestration in Cognitive Internet of Things Solution. Enterprise Information

Systems, 12(1): 1-21;

[14] Maksimovic, M. (2017), The Role of Green Internet of Things (G-IoT) and Big Data in Making Cities Smarter, Safer and More Sustainable. International Journal of Computing and Digital Systems, 6(4): 175-184;

[15] Miorandi, D., Sicari, S., De Pellegrini, F., Chlamtac I. (2012), Internet of

Things: Vision, Applications and Research Challenges. Ad Hoc Networks, 10: 1497-1516;

[16] Mochizuki, Y., Fadeeva, Z. (2010), Competences for Sustainable

Development and Sustainability. International Journal of Sustainability in Higher

Education, 11(4): 391-403;

[17] Mudaly, S., Singh, P., Olugbara, O.O. (2013), Improved Technology

Acceptance Model Applied to Study Enterprise Resource Planning Usage. The

Science and Information Conference, www.conference.thesai.org. accessed 10

November 2020;

[18] Murray, A., Skene, K., Haynes, K. (2017), The Circular Economy: An

Interdisciplinary Exploration of the Concept and Application in a Global

Context. Journal of Business Ethics, 140: 369-380;

[19] Popli, S., Jha, R.K., Jain, S. (2019), A Survey on Energy Efficient

Narrowband Internet of Things (NBIoT): Architecture, Application and

Challenges. IEEE Access, 7: 16739-16776;

[20] Pramanik, P.K.D., Pal, S., Choudhury, P. (2019), Green and Sustainable

High-Performance Computing through Smartphone Crowd Computing. Scalable

Computing: Practice and Experience, 20(2): 259-284;

[21] Rotariu, T. (1999), Eșantionarea. In T. Rotariu (ed.) Metode statistice

aplicate în științele sociale; Iași: Polirom;

[22] Sas, C., Neustaedter, C. (2017), Exploring DIY Practices of Complex Home

Technologies. ACM Transactions on Computer-Human Interaction, 24(2): 1-29;

[23] Venkatesh, V., Morris, M., Davis, G., Davis, F. (2003), Technology

Acceptance Model. MIS Quarterly, 27(3): 247-478;

[24] Wang, J., Hu, C., Liu, A. (2017), Comprehensive Optimization of Energy

Consumption and Delay Performance for Green Communication in Internet of

Things. Mobile Information Systems, volume 2017: 1- 17;

[25] World Economic Forum (2019), A New Circular Vision for Electronics:

Time for a Global Reboot, January, p 10.

DOI: 10.24818/18423264/55.2.21.07 